\title{
HARNESSING THE POWER OF SIMULATION IN THE PROJECT MANAGEMENT / DECISION SUPPORT ASPECTS OF THE CONSTRUCTION INDUSTRY
}

\author{
Gunnar Lucko \\ Department of Civil Engineering \\ 620 Michigan Avenue NE \\ The Catholic University of America \\ Washington, DC 20064, USA
}

\author{
Perakath C. Benjamin \\ Knowledge Based Systems, Inc. \\ 1408 University Drive East \\ College Station, TX 77840, USA
}

\author{
Michael G. Madden \\ M. Madden OR \& DES Consulting \\ 2570 Red Maple Place \\ Melbourne, FL 32955, USA
}

\begin{abstract}
This paper reviews the history of construction simulation systems in light of their graphical representation of complex scenarios. The simulation of construction operations has been a growing field of research over the last several decades. Since the introduction of the first simulation system, which was based on the activity cycle diagram paradigm of modeling, numerous additional tools have been introduced, each building on and expanding the modeling and analytical capabilities of previous approaches. However, despite such rich body of knowledge, which by now is expanding into areas such as visualization, animation, and virtual reality applications for construction project management, the beneficial application of simulation in practice has been marginal. This paper describes both historical and practical reasons for this situation and presents an ontology-based approach that can harness existing information in construction project management, especially the scheduling function, and has the potential to significantly improve its operational planning and optimization.
\end{abstract}

\section{INTRODUCTION}

Construction operations are characterized by an intensive use of physical resources, which include laborers of various skills and crafts, small tools, different types of heavy construction equipment, bulk and discrete materials, custom-made installations, and temporary and permanent support structures. Several of them typically collaborate in an intricately choreographed sequence within the spatial confines of the construction site and the unfinished structure itself. The configuration of the site and the structure change as construction progresses, creating a need to consider various states in the analysis of the entire operation.

Most larger construction projects are uniquely designed and built as one-of-a kind solutions, e.g. roadway projects, bridges, and high-rise buildings. Even smaller projects, e.g. multiple residential buildings in a new urban development, are typically unique, e.g. from different soil conditions at each exact location. However, construction operations also bear a significant amount of repetition that can be modeled for improvements in productivity from learning effects and efficiency gains. Such repetition may occur at different levels of planning, e.g. at a high level when erecting the aforementioned residences, who all may have the same scope. At an intermediate level, repetition may be found in constructing multiple floors of the same footprint for a high-rise building. And at a detailed level, several apartments on each floor are painted. Simulation is ideally suited to analyze any such repetitive operations.

\section{SIMULATION}

Simulation is a powerful technique to dynamically design, analyze, and optimize the complex processes that occur in construction projects. As "a broad collection of methods and applications to mimic the behavior of real systems" (Kelton et al. 2007, p1), it entails developing a numerical model that contains all of the contents and structure of the real-world system, at a specific level of detail and within a specific scope, to answer questions about the behavior of the system. Computer simulation is particularly useful to analyze systems that include randomness in their parameters or where no exact analytical solution exists. For analyzing such complex system, it often is the only scientific methodology available and feasible for practitioners. Simulation facilitates experimentation with real-world systems that would either be impossible, dangerous, or time or cost prohibitive otherwise. It allows precise control of their influencing factors and can be rapidly replicated multiple times to gain statistical measures of mean and variability. Decision makers can thus evaluate options and optimize the performance in terms of time, cost, or productivity.

Visualizations of simulations use the output of a computer simulation model to create either simple schematic or highly realistic graphical representations that help decision makers to better understand the behavior of their system. 


\subsection{Discrete Event Simulation}

Discrete-event simulation (DES) assumes that a dynamic process can be modeled as a chronological list of discrete events, reducing the computational effort (Martínez 1996). Any point in time when an element of the simulation model incurs a state change constitutes an event. Examples are when activities acquire resources upon their start and release them upon their finish, where they turn from active to idle again. Several events can occur at the same time.

\subsection{Activity Cycle Diagrams}

Graphical methods play an important role in the design of simulation models and help clearly communicate the structure and logic of the model to all simulation project team members. Different graphical methods have been used in simulation modeling over the years. Developed at about the same time as the critical path method of scheduling (Kelley and Walker 1989) that relies on network diagrams of interconnected activities, graphical models were formalized first as wheel charts (Martínez 1996), looping structure of repetitive activities that were symbolized as circles (Youle et al. 1959) or as rectangles, e.g. for the model of a steel plant where cranes loaded ore into furnaces (Tocher 1961). The latter symbol has persisted. Based on queuing theory, the circles symbolize queues that store and release resources. These activities and queues are linked to form activity cycle diagrams (ACD) (Paul 1993), which are used to depict simulation models and support entire simulation systems, e.g. the activity cycle based modeling (Shi 1997).

Figure 1, generated with EZStrobe (Martínez 1998), shows the smallest possible ACD. One resource is stored in a queue, used in one activity when its conditions are fulfilled and released at its completion. Note the distinction under the three-phase activity scanning approach (Martínez 1996) into clock advance, executing normals that are 'bound' to start upon completion of a predecessor, and 'conditional' activities, or combis, that first check which startup conditions exist and then pull the required amounts of resources. Combis are computationally more expensive.

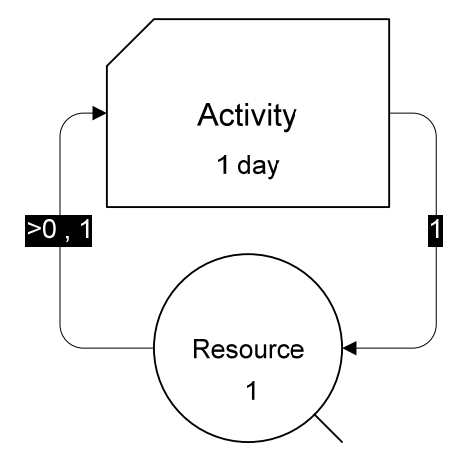

Figure 1: Elementary Activity Cycle Diagram
Queues are modeling constructs that represent 'waiting spaces' in the real world. They provide valuable information for simulation analysis. Since typically multiple 'flow objects', i.e. resource entities, move through a system, the time spent in a queue and its content can help evaluating work-in-process inventories or efficiencies in planning. On construction projects, the movement of items is determined by an activity list, a description of things that need to be done to a build e.g. a section of a roadway or a floor of a high-rise building. If activities are held up waiting for resources or for states to become available, then better planning, more resources, or balancing the operation is needed.

Traditionally, the ACD network of a simulation model alternates between activities and queues. The aforementioned distinction between normals and combis in construction simulation eliminates queues between pairs of normals, where they would not add to an analysis. Queues can thus confuse novice users who seek to develop models. While conceptually activities alone are sufficient for a model to function, which would then resemble a classic construction schedule, queues are a versatile construct to model complex startup conditions, e.g. with 'dummy' resources, or to give signals about states within the system.

\subsection{Construction Simulation Systems}

The first computer system for simulating construction operations was derived from ACDs. The cyclic operations network (CYCLONE) was a DES system specifically created for use in construction (Halpin 1973), which has seen several offsprings. It uses numbered normals, combis, and queues that contain generic resources that are moved via function nodes. An accumulator flag is needed to collect productivity data for the system. Martínez (1996) described its modeling limitations, e.g. the inability to distinguish resources or implement operations functions based on states.

"RESQUE [the resource-based queuing network simulation] was designed as a significant enhancement to CYCLONE where the model is not limited to the information conveyed by the network" (Martínez 1996, p13). It eliminates function nodes and accumulators, supports individual resources and allows some access to the internal state of the simulation for operations functions written in its programming language (Chang 1986). As a setback, this language is not object-oriented but uses numerical labels of commands. Resources are discrete with only one property.

While it is described as "a network-based simulation model" (Liu 1991, p37), the construction object-oriented process simulation (COOPS) system allows specific, individual resources that have calendars, has some probability distributions for activity durations, and offers a menudriven graphical user interface (GUI). However, it uses flags for stopping conditions and also function nodes and is unable to model complex startup conditions or customizable runs or output due to lack of a programming language. 


\section{Lucko, Benjamin, and Madden}

Different from previous systems, the construction integrated project and process planning and simulation (CIPROS) takes a knowledge-based approach. Based on CYCLONE, it is not a programming language, but allows operations functions and features an expandable hierarchy of discrete or bulk resources that can have many different properties (Odeh 1992). Moreover, an expandable hierarchy of class components can be defined, somewhat akin to a work breakdown structure (WBS), a construction estimating taxonomy. Such "[c]onstruction methods form the link between project and process planning" Tommelein et al. (1994a), which makes this simulation system remarkable for its working across different levels of detail. However, there is no access to states (Martínez 1996, p13), no prioritization, and three types of links in addition to arcs and four types of queues may complicate models. The knowledge base of the prototype contained only eight initial entries. Users are left to manually input additional 'method models', i.e. standard sub-network of typical construction processes via a drop-down menu structure. While it was claimed that users would over time populate and reuse method models (Odeh 1992) or templates, other authors have strongly spoken against their use (Martínez 1996, p409f): "No matter how many templates a system provides, however, the diverse and complex nature of construction processes will always require a function of a form not foreseen by the system designer (or requiring a choice of operands or operators not provided in the template)." This would be especially true for innovative techniques.

The hierarchical simulation modeling (HSM) system creates CYCLONE models in a menu-based GUI. Its steps to build the model include a WBS, a resource library, specifying a sequence, and assembly. It specifically addresses the random nature of construction processes and the dynamic utilization of their resources (Sawhney 1994).

Resource-based modeling (RBM) features a menubased GUI to specify resources and site conditions and interact with a library of earthmoving processes and resources (Shi 1995). Several other previous construction simulation systems, including several approaches towards 4D visualization, are omitted in this review for brevity.

A system that defined the state-of-the-art for DES of construction processes, is the state and resource based simulation of construction processes (STROBOSCOPE) system. Notable are its extensible programming language, "ability to assign values" of resource properties during runs and use them, "perform multiple replications" by various methods, handle "derived quantities such as cost", "call functions... in conventional programming languages", and use many predefined probability distributions (Martínez 1996, p462). Later it was extended by EZStrobe (Martínez 1998), a GUI where ACDs can be drawn and debugged to be automatically converted into code. By now, additional systems are building on STROBOSCOPE, notably the visualization of simulated construction operations
(VITASCOPE) system that provides a parametric language for integrated visualization and animation. It postprocesses simulation output files with computer-aided design (CAD) models of construction equipment, the facility under construction, and the environment. The visualization then shows resources moving and interacting while the facility grows (Kamat 2003). Recent studies continue this work by creating an augmented reality tool with global positioning system that overlays the real world with visualization views (Behzadan and Kamat 2005) and by implementing active feedback mechanism from the visualization to the simulation model (Rekapalli and Martínez 2007).

A different approach was taken by the Simphony framework for production-based modeling and analysis (AbouRizk and Mohamed 2002). It provides a platform for project managers to develop special purpose simulation tools (AbouRizk and Hajjar 1998) by customizing various components, "including a discrete event simulation engine, a trace manager, statistics collection, graphing, random numbers generation, and report generation" (Sawhney et al. 2001, p1522), into a template within which models can be created (AbouRizk and Mohamed 2000). Use of templates was validated with different production scenarios for building a group of residences (Sawhney et al. 2001). Alternative simulation 'world views' that are appropriate for construction applications were identified (AbouRizk and Mohamed 2002, p1707). They move beyond DES to incorporate "subjective modeling, state-based modeling, and continuous process modeling." Including "subjective information' from domain expert in simulation models would require techniques such as "fuzzy set theory, artificial neural networks, Bayesian statistics, and other fields".

Kannan et al. (2000, p. 1946f.) contrast general and special purpose simulators, whereby the latter ones involve information specific to a domain. "It is also important to point out that most special purpose simulators are based on general-purpose simulation programs and so, share the modeling paradigm. A majority of the special purpose simulators use an intuitive user interface to translate a users requirement into secondary computer code, which in turn is interpreted by a simulation engine. Most of the existing simulation programs (...) do not use domain knowledge as part of the interface or the simulation engine."

This need for knowledge capture and the coding that is required to refine individual templates in a special purpose simulation or to define various object classes in the modular architecture of a time and cost optimization system for earthmoving equipment (Marzouk and Moselhi 2000) reinforce the need for a comprehensive knowledge based approach in modeling and analyzing construction operations.

\subsection{Reasons for Lacking Practical Use}

The literature contains numerous example applications of the aforementioned simulation systems to model construc- 
tion processes (Halpin and Martínez 1999), e.g. earthmoving (Ioannou and Martínez 1996), concrete production (Zayed and Halpin 2001), pile driving (Zayed and Halpin 2004), road building (Hassan and Gruber 2008) and others. Despite the enormous potential of simulation, its actual implementation in industry practice is lacking strongly. An industrial engineering study found that impediments to its widespread application, including "education, training, and expertise" (Garnett 1999, p47). Reasons cited most frequently include the time, cost, and effort (Benjamin et al. 2002) required to learn a simulation system or language for simulating a project, including model verification and validation, before any benefits can be realized whatsoever. Numerous scholarly publications echo these sentiments.

Lingineni et al. (1995, p408) list that "current simulation practice 1) affords little support for the initial analysis and model design tasks which are largely quantitative in nature, 2) involves the unproductive use of both the domain expert's and the simulation analyst's time in the modeling process, and 3) suffers from lack of widespread acceptance by decision makers due to the relatively long lead times and sophisticated skills needed for the effective use of simulation modeling techniques." Son and Wysk (2001, p292) concur: "Unless the time-consuming phase of learning and using a simulation language is reduced, the advantages of simulation cannot be fully exploited". Nowhere is this truer than in the construction industry, whose two major needs are advanced technology and skilled labor (National Science Foundation and FIATECH 2004). To overcome the holdbacks and widen its use in the construction industry, model creation should be automated (Odeh 1992, p53): "CIPROS is not an automated planner, and thus it neither creates the process network nor checks its correctness. It is up to the user to define a process network that is correct in terms of both scope and precedence."

\section{CONCEPTUAL APPROACH}

These authors propose the concept of a knowledge based approach that focuses attention on the preliminary aspects of the simulation process, beginning with the acquisition and a system description, followed by its analysis, and culminating in the design of a conceptual simulation model. It anticipates both the need for modeling and analysis frameworks and the need for multiple modeling views or paradigms. This approach is founded on an important research hypothesis: A knowledge-based approach to build automated support for simulation modeling needs to be $d e-$ scription-centered. When asked to explain a problem, domain experts often find it convenient to communicate their knowledge by relating an ordered sequence of activities that describes 'how things work' in their domain. Much of the knowledge needed to reason about the problem to be solved can thus be found within the description itself. To support the discovery process along the way to building idealized models from such unstructured descriptions, it is necessary to have both a language and a method to acquire, represent, and reason with said descriptive knowledge.

The use of such a knowledge based approach can produce the following benefits for modeling and simulation applications: (1) Reduce the tight coupling and dependency between domain experts and simulation analysts; (2) facilitate effective communication between domain experts and simulation analysts; (3) enable the accurate translation of system descriptions and design goals into executable simulation code; and (4) minimize the need for extensive and costly training in order to use simulation technology.

\subsection{Ontologies}

Ontological research seeks to categorize and structure information that exists about complex processes and how their elements interact with each other. A formal definition was provided by Benjamin et al. (1995, p225): “An ontology is a description of the kinds of things, both physical and conceptual, that make up a given domain, their associated properties, and the relationships that hold among them as represented by the terminology of that domain." Fishwick and Miller (2004, p260) underlined the importance of standardizing ontologies "to form communities intent on sharing the knowledge", e.g. by project managers and other professional decision makers in the construction industry.

\subsection{Integrated Modeling Definition Languages}

Ontology research has developed the integrated modeling definition (IDEF) family of methods for various applications in data structuring and analysis. It has its origins in the business and military environment, but is in the public domain as a neutral symbolic system of semantics and syntax (Mayer et al. 1992). IDEF has the advantage of being a well-established approach whose various methods are fully integrated with each other, including IDEF3 for process flow and object state description capture, IDEF4 for object-oriented design, and IDEF5 for ontology description capture. Other modeling languages exist, e.g. the generic process modeling method (Karhu 2001), but they suffer from being overly general in trying to suit most possible applications and are largely rendered useless (Bell 2004).

For example, the IDEF3 process knowledge modeling method used by the U.S. Air Force is based upon the concept of direct capture of facts about processes and events in a form that is natural to domain experts in a given environment. This includes the capture of facts about the objects that participate in a process, facts about object state transitions, as well as the precedence and causality relations between processes and events. The goal of IDEF3 is to provide a structured method for expressing a domain expert's knowledge about how a particular system or organization works. In particular, an IDEF3 description can 
be used to record the raw data resulting from fact finding interviews in systems analysis activities. IDEF3 addresses the concerns of process and system description with a definition language that allows organizing and expressing descriptive facts from which many possible models may be designed. More information about integrated definition methods is available at $\langle$ http: / /www. idef.com $>$.

\subsection{Necessary Structure and Content Data}

According to Benjamin et al. (2006, p1154f), several items must be fulfilled in order to develop simulation models:

- Establishment of model boundaries. Each simulation model only covers a specific range of the real world that it seeks to represent. The user must select lower and upper boundaries, or an envelope, within which all modeling and analysis will commence. For a construction simulation, the extent of the project across time and space provides such envelope, unless smaller parts shall be examined.

- Establishment of level of abstraction. Strongly related with the boundaries of the model is its level of abstraction or resolution. In this case, the timehonored principle Occam's razor applies that the model should be as complicated as necessary but as simple as possible. The determining factor for a construction simulation lies in the level of detail that exists in the project management systems.

- Identification of model objects and roles. Once the model boundaries and resolution are established, its elements and their relationships need to be determined. As mentioned before, the number and sequencing of activities and queues forms the structure of the model while adhering to rules on normals and combis. Durations of activities, contents of queues, and conditions for their storage and release are information of the model content.

The central research hypothesis of this paper allows that descriptions of processes and the knowledge by the domain expert can be viewed separately from the computer code that will ultimately represent the simulation model for numerical analysis. Applying this concept to the construction industry, where it is so strongly needed to enable an increased beneficial use of simulation technology, the first aspect necessarily takes center stage. The use of ontologies for knowledge capture of construction processes then become a scientific problem that hinges on two conditions. First, it is necessary that the elements of the process must involve specific known resources. Second, it is desirable, but not necessary, that the process exhibit a certain degree of repetition in the sequence of its elements. For applying the knowledge based approach to the construction industry, this means especially that existing systems where descrip- tions of processes are routinely created, manipulated, and stored by project managers, would have to be data mined. Since all construction projects undergo an initial planning phase, the information created therein could be leveraged toward the automatic generation of simulation models.

Knowledge capture occurs in form of scheduling software and - to a lesser degree - also estimating software. Data in a typical schedule file contain information about the structure and the contents the construction process at hand. This includes listing of individual activities, their names and descriptions, planned and/or actual durations, connectivity (precedence) and type of linkage (either as finish-to-start, finish-to-finish, start-to-finish, or start-tostart relationship), and required resources and their respective calendars and availability for each activity. Estimating databases can supply additional information that includes an ontology-like organization system (widely known as work breakdown structure) for all items to be physically constructed, their quantities and units of measurement, cost of materials, labor, and equipment (if applicable), and possibly the productivities achieved by the respective labor and equipment resources (which combined with the quantities yield the durations in the schedule). While companies may set up their own customized work breakdown structures, standardized systems are widely used, including the UniFormat and MasterFormat, or the new international OmniClass Construction Classification System (OCCS).

Hence, the use of templates or method models can be avoided, along with the difficulties of simulation users having to create and maintain a large library thereof, as described above. At the same time, the time-consuming and cost-inducing phase of users having to learn a simulation language at least to a degree where correct and complete models can be created and run, is avoided as well. On the contrary, following this new approach the decision makers of the construction industry would almost instantaneously have complete simulation models at their disposal that reflect the knowledge that they would have previously incorporated into their existing project management systems.

\subsection{Automatic Simulation Generation}

Early generic simulation generators required manually entering process information (Oldfather et al. 1966), akin to programming in a simulation language (Paul and Chew 1987). Another system used operations equations to describe inputs and outputs of each activity, only used unspecific resources, and omitted queues (Yuan et al. 1993). A process modeling tool used the standard for exchanging product data by the International Standardization Organization and IDEF to semantically analyze data and was tested for precast concrete operations (Lee 2004), but lacked true simulation capabilities. Initial approaches to automated simulation focused on space operations, including generic models for the space shuttle missions (Cates and Mol- 
laghasemi 2005) and its ground processing (Madden et al. 2005), which required mining vast amounts of prior process data. Studies have worked on automating simulations of processes for business enterprises (Benjamin et al. 1998) and the manufacturing industry (Son 2000, Waller and Ladbrook 2002). However, work in manufacturing shops differs a lot from construction projects. The resource-centered process interaction approach works best for manufacturing, where individual products move along a controlled production line between fixed machines; the activity-centered activity scanning approach works best for construction, with "heavy interaction between machines, each of which can occupy different locations, have many attributes, and be in several states" (Martínez 1996, p7).

\section{ENABLING TECHNOLOGY}

Contemporary DES tools (e.g. Arena, Witness, ProModel, Extend, etc.) are designed to support industry-wide requirements for process modeling and analysis. Many of these commercial packages were originally developed to simulate manufacturing and logistics processes, which are characterized by known flows of parts-in-progress between service stations in a controlled factory environment. The capabilities offered by these tools are generic and they typically cannot be customized well to application domains that are outside the scope of discrete part manufacturing.

As stated earlier in this paper, current simulation tools provide inadequate support for the initial analysis and model design tasks in simulation, leading to unproductive use of both the domain expert's and the simulation analyst's time in the modeling process (Lingineni et al. 1995). Recent advances in knowledge based systems development and semantic technologies offer a solution to this problem. An approach such as the one described in this paper for the specific application in the construction industry has the potential to significantly improve the process of creating simulation models and by extension also to increase and improve their use in practice. For example, ontological analysis has been shown to be an effective initial step in the design and development of intelligent systems. Moreover, the popularity of semantic technologies and the semantic web has provided several beneficial opportunities for the modeling and simulation communities of interest (Benjamin et al. 2007), e.g. medicine and the military. However, the simulation community has yet to take advantage of the benefits of ontology management technology.

\subsection{WorkSim}

WorkSim is an advanced object-oriented knowledge based simulation based planning and scheduling framework (Benjamin et al. 2005). It has been designed to address the process analysis needs of large-scale organizations. It consists of a central database, a model generator, and schedul- ing, simulation, and optimization engines. While it has not yet been adapted for simulation of construction processes, it fulfills the requirements that have been outlined earlier in this paper. Input can be read from its own database files, Microsoft ${ }^{\circledR}$ Project schedules, or from the ProSim ${ }^{\circledR}$ tool.

WorkSim captures all relevant schedule data including activity precedence and types of linkage, durations, priorities, resource calendars, etc. and uses these data to generate simulation models of the project that can be optimized by techniques such as genetic algorithms and simulated annealing. It offers customizable reporting functions to extract specific information from the generated plans for documentation. Data can be exported from WorkSim to other project management tools, e.g. Microsoft ${ }^{\circledR}$ Project or Microsoft ${ }^{\circledR}$ Excel, to show e.g. optimal start and finish dates for activities and their resource requirements per hour, day, week, month, or year for the entire project.

Its knowledge based approach allows users to quickly update activities and resources in the underlying database whenever unexpected changes occur in the real-world production system. Users can then simply rerun the WorkSim simulation engine to generate a revised plan that shows the impact of those changes on the overall project execution.

\subsection{Aerospace Application Example}

WorkSim has been used to address to operations analysis needs of the aerospace industry. The prototype system used the Toolkit for Enabling Adaptive Modeling and Simulation (TEAMS), a modular software architecture that allows collaborative and distributed analysis of spaceport operations within a highly customizable framework (Benjamin et al. 2002). It was demonstrated on a real life application at Kennedy Space Center. The specific effort was creating a model for the ground processing model of the space shuttle (Madden et al. 2005). Notable characteristics of this process included a strong emphasis on states as conditions for activities to start (e.g. orbiter powered up or not, payload bay doors open or not, etc.) and a significant amount of unplanned activities that may occur during entire ground processing operations. Frequent planned inspections can lead to additional unplanned repair activities, which add sub-networks of activities into the existing schedule. Creating simulation models automatically from the schedules of such complex project, which encounters a ratio of $40 \%$ planned activities to $60 \%$ unplanned activities during a typical mission, has proven to be challenging. Project managers know of the unplanned effort but cannot be certain of the exact items that will need repair. The workforce needs to be augmented to absorb the added activities and the plan is reworked each day with up to four daily schedule updates to incorporate the latest items to be repaired. The TEAMS system uses the IDEF3 process modeling method and includes simulation, schedule, and cost-analysis functionality. WorkSim can be used to rapidly generate DES 
models for this and other complex processes and subsequently optimize their performance (Madden et al. 2005).

\section{CONCLUSIONS AND RECOMMENDATIONS}

The construction industry of the $21^{\text {st }}$ century faces unique challenges in terms of an increasing need toward higher productivity, shorter durations, and lower cost, attenuated by the needs for skilled labor and beneficial use of technology. This paper has given an overview of existing simulation systems that sought to bring simulation and optimization capabilities to decision makers in the construction industry. They are found to have been strongly influenced by a graphical approach to simulation, as ACDs are closely related to the network diagrams used in scheduling. Despite decades of research on such construction simulation systems, each of which made important improvements over previous ones, none have become a widely accepted project management tool. While advanced research on visualization of simulated construction operations is continuing and strongly expanding, as of the current time a fundamental challenge has been left unaddressed, the need to automate the creation of simulation models. The contribution of this paper is to call attention to this gap in the body of knowledge. It proposes a knowledge based approach using ontologies, instead of the traditional graphically based one, to harness existing project management information to significantly improve operations planning and optimization. It would thus extend and enhance the previous approach of special purpose simulators to use domain-specific information, while at the same time vastly reducing the effort of model development by extracting data from planning systems with which the project managers are already familiar.

The very nature of construction, which concerns itself with constructing large-scale physical facilities using a multitude of different resources in the face of uncertainty in numerous influential factors makes it an ideal candidate for analysis with simulation. While it does encounter unplanned rework, its proportion is typically much smaller than that encountered in the spaceport operations. As mentioned before, constraints of limited resource availability are a constant problem in construction, which is compounded by variability in the actual activity durations. In fact, "the most commonly understood example of a resource constrained-project scheduling problem with stochastic durations" is found in construction projects (Madden et al. 2005, p1258), which are planned and scheduled with the simplifying assumption of known activity durations under the critical path method. Probabilistic scheduling with the program evaluation and review technique exists but is used infrequently (Galloway 2006). Overall, there thus is tremendous potential for the construction industry to finally expand its use of simulation as a powerful modeling and analysis methodology as facilitated by the knowledge based approach that is outlined in this paper.

\section{REFERENCES}

AbouRizk, S. M., Hajjar, D. 1998. A framework for applying simulation in construction. Canadian Journal of Civil Engineering 25(3): 604-617.

AbouRizk, S., Mohamed, Y. 2002. Optimal construction project planning. Proceedings of the Winter Simulation Conference, eds. Yücesan, E., Chen, C.-H., Snowdon, J. L., Charnes, J. M., IEEE, Piscataway, NJ: 1704-1708.

AbouRizk, S., Mohamed, Y. 2000. Simphony - an integrated environment for construction simulation. Proceedings of the Winter Simulation Conference, eds. Joines, J. A., Barton, R. R., Kang, K., Fishwick, P. A., IEEE, Piscataway, NJ: 1907-1914.

Behzadan, A. H., Kamat, V. R. 2005. Visualization of construction graphics in outdoor augmented reality. Proceedings of the Winter Simulation Conference, eds. Kuhl, M. E., Steiger, N. M., Armstrong, F. B., Joines, J. A., IEEE, Piscataway, NJ: 1914-1920.

Bell, A. E. 2004. Death by UML fever: Are you (or your developers) sick? ACM Queue 2(1): 72-80, $<$ http://www.acmqueue.com/modules.php?name=Cont ent\&pa $=$ showpage\&pid=130>, August 1, 2007.

Benjamin, P. C., Delen, D., Erraguntla, M. 1998. An introduction to using ProSim for business process simulation and analysis. Proceedings of the Winter Simulation Conference, eds. Medeiros, D. J., Watson, E. F., Carson, J. S., Manivannan, M. S., IEEE, Piscataway, NJ: 315-321.

Benjamin, P. C., Graul, M., Erraguntla M. 2002. Toolkit for enabling adaptive modeling and simulation (TEAMS). Proceedings of the Winter Simulation Conference, eds. Yücesan, E., Chen, C.-H., Snowdon, J. L., Charnes, J. M., IEEE, Piscataway, NJ: 763-771.

Benjamin, P. C., Akella, K. V., Malek, K., Fernandes, R. 2005. An ontology-driven framework for processoriented applications. Proceedings of the Winter Simulation Conference, eds. Kuhl, M. E., Steiger, N. M., Armstrong, F. B., Joines, J. A., IEEE, Piscataway, NJ: 2355-2363.

Benjamin, P. C., Patki, M., Mayer, R. 2006. Using ontologies for simulation modeling. Proceedings of the Winter Simulation Conference, eds. Perrone, L. F., Wieland, F. P., Liu, J., Lawson, B. G., Nicol, D. M., Fujimoto, R. M., IEEE, Piscataway, NJ: 1151-1159.

Benjamin, P. C., Akella, K. V., Verma, A. K. 2007. Using ontologies for simulation integration. Proceedings of the Winter Simulation Conference, eds. Henderson, S. G., Biller, B., Hsieh, M.-H., Shortle, J., Tew, J. D., Barton, R. R., IEEE, Piscataway, NJ: 1081-1089.

Cates, G. R., Mollaghasemi, M. 2005. A discrete event simulation model for assembling the international space station. Proceedings of the Winter Simulation Confer- 
ence, eds. Kuhl, M. E., Steiger, N. M., Armstrong, F. B., Joines, J. A., IEEE, Piscataway, NJ: 1260-1264.

Chang, D. Y.-M. 1986. RESQUE: A resource based simulation system for construction process planning. Dissertation, University of Michigan, Ann Arbor, MI.

Fishwick, P. A., Miller, J. A. 2004. Ontologies for modeling and simulation: Issues and approaches. Proceedings of the Winter Simulation Conference, eds. Ingalls, R. G., Rossetti, M. D., Smith, J. D., Peters, B. A., Washington, IEEE, Piscataway, NJ: 259-264.

Garnett, J. 1999. The last word on simulation. IIE Solutions 31(1):45-47.

Galloway, P. D. 2006. Survey of the construction industry relative to the use of CPM scheduling for construction projects. Journal of Construction Engineering and Management 132(7): 697-711.

Halpin, D. W. 1973. An investigation of the use of simulation networks for modeling construction operations. Dissertation, University of Illinois, UrbanaChampaign, IL.

Halpin, D. W., Martinez, L.-H. 1999. Real world applications of construction process simulation. Proceedings of the Winter Simulation Conference, eds. Sturrock, D. T., Evans, G. W., Farrington, P. A., Nemhard, H. B., IEEE, Piscataway, NJ: 956-962.

Hassan, M. M., Gruber, S. 2008. Simulation of concrete paving operations on Interstate-74. Journal of Construction Engineering and Management 134(1): 2-9.

Ioannou, P. G., Martínez, J. C. 1996. Simulation of complex construction processes. Proceedings of the Winter Simulation Conference, eds. Brunner, D. T., Swain, J. J., Charnes, J. M., Morrice, D. J., IEEE, Piscataway, NJ: 1321-1328.

Kamat, V. R. 2003. VITASCOPE: Extensible and scalable $3 D$ visualization of simulated construction operations. Dissertation, Virginia Polytechnic Institute and State University, Blacksburg, VA.

Kannan, G., Schmitz, L., Larsen, C. 2000. An industry perspective on the role of equipment-based earthmoving simulation. Proceedings of the Winter Simulation Conference, eds. Joines, J. A., Barton, R. R., Kang, K., Fishwick, P. A., IEEE, Piscataway, NJ: 1945-1952.

Karhu, V. 2001. A generic construction process modelling method: A model based approach for process description. Dissertation, Royal Institute of Technology, Stockholm, Sweden.

Kelley, J. E., Walker, M. R. 1989. The origins of CPM: A personal history. PM Network 3(2): 7-22.

Kelton, W. D., Sadowski, R. P., Sturrock, D. T. 2007. Simulation with ARENA. $4^{\text {th }}$ ed., McGraw-Hill, New York, New York.

Lee, G. 2004. A new formal and analytical process to product modeling (PPM) method and its application to the precast concrete industry. Dissertation, Georgia Institute of Technology, Atlanta, GA.
Lingineni, M., Caraway, Benjamin, P. C., Mayer, R. J. 1995. A tutorial on PROSIM ${ }^{\mathrm{TM}}$ : A knowledge-based simulation model design tool. Proceedings of the 1995 Winter Simulation Conference, eds. Alexopoulos, C., Kang, K., Lilegdon, W. R., Goldsman, D., IEEE, Piscataway, NJ: 408-412.

Liu, L.-Y. 1991. COOPS - construction object-oriented process simulation system. Dissertation, University of Michigan, Ann Arbor, MI.

Madden, M. G., Wyrick, R., O’Neill, D. E. 2005. A strategy for autogeneration of space shuttle ground processing simulation models for project makespan estimation. Proceedings of the Winter Simulation Conference, eds. Kuhl, M. E., Steiger, N. M., Armstrong, F. B., Joines, J. A., IEEE, Piscataway, NJ: 1251-1259.

Martínez, J. C. 1996. STROBOSCOPE: State and resource based simulation of construction processes. Dissertation, University of Michigan, Ann Arbor, MI.

Martínez, J. C. 1998. EZStrobe - General-purpose simulation system based on activity cycle diagrams. Proceedings of the Winter Simulation Conference, eds. Medeiros, D. J., Watson, E. F., Carson, J. S., Manivannan, M. S., 1998, IEEE, Piscataway, NJ: 341-348.

Marzouk, M., Moselhi, O. 2000. Optimizing earthmoving operations using object-oriented simulation. Proceedings of the Winter Simulation Conference, eds. Joines, J. A., Barton, R. R., Kang, K., Fishwick, P. A., IEEE, Piscataway, NJ: 1926-1932.

Mayer, R. J., Painter, M. K., deWitte, P. S. 1992. IDEF family of methods for concurrent engineering and business re-engineering applications. Report, Knowledge Based Systems, College Station, Texas, $<$ http://www.idef.com/pdf/IDEFFAMI.pdf $>$, August 1, 2007, 77p.

National Science Foundation, FIATECH (2004). An interdisciplinary charette: Setting an academic research agenda for the FIATECH capital projects technology roadmap initiative. Final report, National Science Foundation Grant No. CMS-0439630, prepared by: Dr. Jorge A. Vanegas, Georgia Institute of Technology, Atlanta, Georgia, 257p.

Odeh, A. M. 1992. CIPROS: Knowledge-based construction integrated project and process planning simulation System. Dissertation, University of Michigan, Ann Arbor, MI.

Oldfather, P. M., Ginsberg, A. S., Markowitz, H. M. 1966. Programming by questionnaire: How to construct a program generator. Rand Report RM-5129-PR, Rand Corporation, Santa Monica, California.

Paul, R. J. 1993. Activity cycle diagrams and the three phase method. Proceedings of the Winter Simulation Conference, eds. Russell, E. C., Biles, W. E., Evans, G. W., Mollaghasemi, M., IEEE, Piscataway, NJ: 123-131. 
Paul, R. J., Chew, S. T. 1987. 'Simulation modeling using an interactive simulation program generator.' Journal of the Operational Research Society 38(8), 735-752.

Rekapalli, P. V., Martínez, J. C. 2007. A message-based architecture to enable runtime user interaction on concurrent simulation-animations of construction operations. Proceedings of the Winter Simulation Conference, eds. Henderson, S. G., Biller, B., Hsieh, M.-H., Shortle, J., Tew, J. D., Barton, R. R., IEEE, Piscataway, NJ: 2028-2031.

Sawhney, A. 1994. Simulation-based planning for construction. Dissertation, University of Alberta, Edmonton, Canada.

Sawhney, A., Bashford, H. H., Walsh, K. D., Mund, A. 2001. Simulation of production homebuilding using Simphony. Proceedings of the Winter Simulation Conference, eds. Peters, B. A., Smith, J. S., Medeiros, D. J., Rohrer, M. W., IEEE, Piscataway, NJ: 1521-1527.

Shi, J. 1995. Automated modeling and optimization for construction simulation. Dissertation, University of Alberta, Edmonton, Canada.

Shi, J. 1997. A conceptual activity cycle-based simulation modeling method. Proceedings of the Winter Simulation Conference, eds. Andradóttir, S., Healy, K. J., Withers, D. H., Nelson, B. L., IEEE, Piscataway, NJ: 1127-1133.

Son, Y.-J. 2000. Simulation based shop floor control: Automatic model generation and control interface. Dissertation, The Pennsylvania State University, University Park, PA.

Son, Y. J., Wysk, R. A. 2001. Automatic simulation model generation for simulation-based, real-time shop floor control. Computers in Industry 45(3): 291-308.

Tocher, K. D. 1961. The role of models in operational research. Journal of the Royal Statistical Society 124(2): 121-142.

Tommelein, I. D., Carr, R. I., Odeh, A. M. 1994a. Assembly of simulation networks using designs, plans, and methods. Journal of Construction Engineering and Management 120(4): 796-815.

Waller, A. P., Ladbrook, J. 2002. Experiencing virtual factories of the future. Proceedings of the Winter Simulation Conference, eds. Yücesan, E., Chen, C.-H., Snowdon, J. L., Charnes, J. M., IEEE, Piscataway, NJ: 513-517.

Yuan, Y., Dogan, C. A., Viegelahn, G. L. 1993. A flexible simulation model generator. Computers and Industrial Engineering 24(2): 165-175.

Youle, P. V., Tocher, K. D., Jessop, W. N, Musk, F. I. 1959. Simulation studies of industrial operations. Journal of the Royal Statistical Society 122(4): 484510.

Zayed, T. M., Halpin, D. W. 2001. Simulation of concrete batch plant production. Journal of Construction Engineering and Management 127(2): 132-141.
Zayed, T. M., Halpin, D. W. 2004. Simulation as a tool for pile productivity assessment. Journal of Construction Engineering and Management 130(3): 394-404.

\section{AUTHOR BIOGRAPHIES}

GUNNAR LUCKO is Assistant Professor of Civil Engineering and Director of the Construction Engineering and Management Program in the Department of Civil Engineering at The Catholic University of America. He has a German Diploma in Civil and Environmental Engineering from Hamburg University of Technology and an M.S. and Ph.D. from Virginia Polytechnic Institute and State University (Virginia Tech). His research interests include mathematical representation, simulation, and analysis of schedules, construction equipment operations and economics, optimization methods, constructability analysis, and engineering education. He has studied statistical equipment valuation models, has participated in research for the Construction Industry Institute, and is currently working on research funded by the National Science Foundation. He is a member of ASCE and the INFORMS Simulation Society.

PERAKATH C. BENJAMIN is Vice President (R\&D) at Knowledge Based Systems, Inc. (KBSI), manages and directs the R\&D activities. He has over 18 years of professional experience in systems analysis, design, development, testing, documentation, deployment, and training. He has a Ph.D. in Industrial Engineering from Texas A\&M University. He has been responsible for the development of process modeling, software development planning, and simulation generation tools that are being applied extensively throughout industry and government. At KBSI, he was the principal architect on an NSF project to develop intelligent support for simulation modeling that led to the development of the commercial simulation tool ProSim ${ }^{\circledR}$.

MICHAEL G. MADDEN is President and Senior Consultant at M. Madden OR \& DES Consulting, Inc., a Ph.D. Student in the University of Miami's - Industrial Engineering Program and a former Senior Vehicle Engineer for the space shuttles Endeavour and Atlantis where he worked with the processing team and the test team responsible for technical decisions of the space shuttle process. He now works in the Florida Program Office of United Space Alliance, LLC where he develops simulation and datamining technology for estimation of processing flows. He has an MS in Technology Management from Embry-Riddle Aeronautical University, and a BS-MET from Wentworth Institute of Technology. His research interests are in the resource-constrained scheduling domain, especially in using criticality indices for heuristics, and in operations research problems associated with space shuttle processing and knowledge management. He is a member of IEEE, ACGIH, AIChE, and the INFORMS Simulation Society. 